\title{
A New Locality Record for the Recently Described Laudankia Vinesnake (Ahaetulla laudankia)
}

\author{
Debaprasad Sengupta ${ }^{1}$ and S.R. Chandramouli ${ }^{2}$
}

${ }^{1}$ Wildlife Institute of India, Chandrabani, Dehradun, Uttarakhand-248002, India (debaprasad.sengupta40@hotmail.com)

${ }^{2}$ Department of Ecology and Environmental Sciences, School of Life Sciences, Pondicherry University, Puducherry-605014, India (findthesnakeman@gmail.com)

$\mathrm{O}^{\mathrm{f}}$ f the ten currently recognized species of tropical Asian vinesnakes in the genus Ahaetulla, nine occur on the Indian Subcontinent (Uetz et al. 2020). The Laudankia Vinesnake (Ahaetulla laudankia Deepak, Narayanan, Sarkar, Dutta, and Mohapatra 2019) was described on the basis of three specimens from Odisha in eastern India and Mount Aboo in Rajasthan. Patel et al. (2019) subsequently recorded the species from three localities in Gujarat.

Herein, we report an additional record from the Sariska Tiger Reserve in Rajasthan. A subadult male (SVL $427 \mathrm{~mm}$, tail $230 \mathrm{~mm}$; Fig. 1) was basking on a stem of grass at $0830 \mathrm{~h}$ on 10 December 2017 on the slope of a hill adjacent to Dhok (Anogeissus pendula) dominated forest at Kalighati in the Sariska Range $\left(27^{\circ} 18^{\prime} 09.3^{\prime \prime} \mathrm{N}, 76^{\circ} 25^{\prime} 07.0^{\prime \prime E}\right)$ at an elevation of $578 \mathrm{~m}$ asl. This site is approximately $600 \mathrm{~km}$ northeast of Mount Abu and thus represents the northernmost locality record for this species (Fig. 2). The specimen was accessioned into the collections of the Wildlife Institute of India (WII/ NRW/No_55).

The snake was identified as Ahaetulla laudankia based on the following characters: head long $(18.8 \mathrm{~mm})$ and slender (head width $5.34 \mathrm{~mm}$ ) with a long pointed snout (eyesnout distance $8.03 \mathrm{~mm}$ ) oriented slightly upward; eyes large (ED $3.04 \mathrm{~mm}$ ) with horizontal pupils; eye-nostril distance $4.97 \mathrm{~mm}$ and interorbital distance $(5.10 \mathrm{~mm})$ greater than internarial distance $(1.50 \mathrm{~mm})$. Dorsal scales smooth and in oblique 15:15:13 rows. Ventrals numbered 188; cloacal scale single, subcaudals 171 , loreal absent, supralabials 8 , infralabials 7 , preocular single, postoculars 2 , and temporals $1+2$. The dorsum was light brown, the venter somewhat lighter.

Vinesnakes with superficially similar morphology to those of $A$. laudankia have been reported from Phansad in

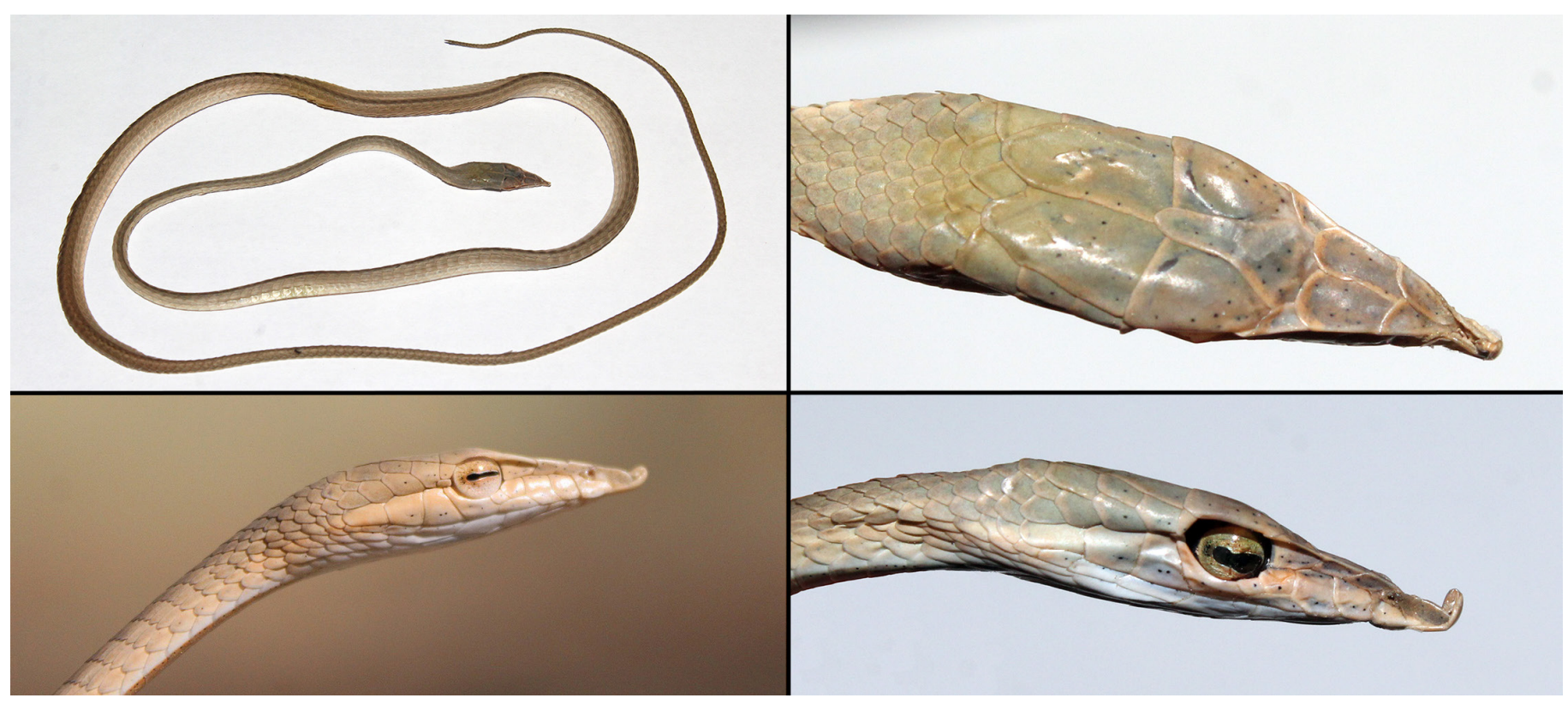

Fig. 1. A Laudankia Vinesnake (Ahaetulla laudankia) (WII/NRW/No_55) from the Sariska Tiger Reserve in Rajasthan. Photographs by Debaprasad Sengupta. 


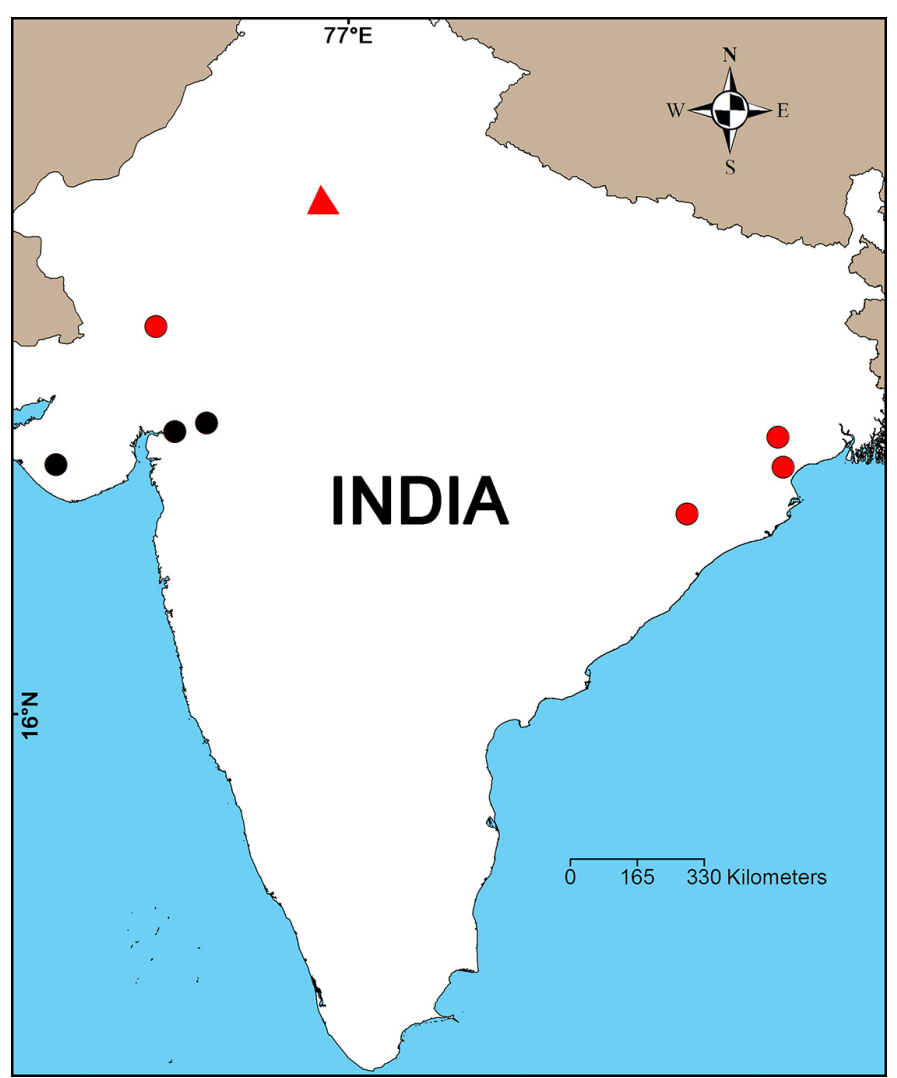

Fig. 2. Known locality records for the Laudankia Vinesnake (Ahaetulla laudankia). Red dots indicate localities recorded by Deepak et al. (2019), black dots those of Patel et al. (2019), and the red triangle marks the new record reported herein from the Sariska Tiger Reserve in Rajasthan.

Maharashtra (Walmiki et al. 2012) and the Nallamalai Hills in Andhra Pradesh (Rao et al. 2005), but the taxonomic sta- tus of those snakes requires confirmation. The limits of this recently described and poorly known species' distribution are not well documented. An awareness of its entire distribution is necessary to assess its conservation status.

\section{Acknowledgements}

The observation reported herein was made under the National Tiger Conservation Authority (NTCA)-funded project, "Monitoring of Reintroduced Tigers in Sariska Tiger Reserve-Phase II." We thank the Rajasthan Forest Department and NTCA for granting permission to conduct studies in the Sariska Tiger Reserve; the Director, Dean and Research Coordinator of the Wildlife Institute of India for their support; Dr. Parag Nigam for supervising the project; Dr. J.A. Johnson for registration of the specimen in the collections of the Wildlife Institute of India; and our field assistants, Ratan Gurjar and Rajesh Meena, for help in the field.

\section{Literature Cited}

Deepak, V., S. Narayanan, V. Sarkar, S.K. Dutta, and P. Mohapatra. 2019. A new species of Ahaetulla Link, 1807 (Serpentes: Colubridae: Ahaetullinae) from India. Journal of Natural History 53: 497-516.

Patel, H., R. Vyas, and P. Vaghashiya. 2019. On the distribution of Ahaetulla laudankia Deepak, Narayanan, Sarkar, Dutta \& Mohapatra, 2019 and Lycodon travancoricus (Beddome, 1870) (Squamata, Colubridae) from Gujarat, India. Check List 15: 1045-1050.

Rao, T.K., H.V. Ghate, M. Sudhakar, S.M.M. Javed, and I.S.R. Krishna. 2005. Herpetofauna of Nallamalai Hills with eleven new records from the region including ten new records for Andhra Pradesh. Zoos' Print Journal 20: 1737-1740.

Uetz, P., P. Freed, and J. Hošek (eds.). 2019. The Reptile Database. <http://www. reptile-database.org>.

Walmili, N., S. Karangutkar, B. Yengal, V. Wagh, A. Kumbhar, A. Jadhav, and A. Khan. 2012. Record of Ahaetulla nasuta var. isabellinus from Phansad Wildlife Sanctuary Raigad-Maharastra, India. Universal Journal of Environmental Research and Technology 2: 196-198. 